\title{
How Testimony Can Be a Source of Knowledge ${ }^{1}$
}

\author{
Nicholas Smith*
}

\begin{abstract}
Much of what we regard ourselves as knowing came to us from the testimony of others. But recently epistemologists have debated just how testimony can be a source of knowledge at all. Must we have some independent way to confirm what we receive through testimony, or is there perhaps some reason why we should suppose that testimony is all by itself an adequate source of knowledge? This problem, I claim, is actually a version of a much older and better known problem: the so-called problem of the criterion. I will first explain this other, older, problem, and lay out the available options for solving it. I will then show why I think the problem of testimony is simply a version of the problem of the criterion. I will conclude by arguing that the best way to solve these problems comes from a theory of justification that few epistemologists seem to support these days: holistic coherence theory. In doing so, I hope I will provide some powerful new reasons for reconsidering this theory of justification.
\end{abstract}

\section{The Problem of Testimony}

There are lots of things we ordinarily think we know. Here are a few examples:

- John F. Kennedy was assassinated in Texas.

- The world existed before any of us was born.

- Smoking causes cancer.

- The moon orbits the earth.

Now, of course, radical skeptics will deny that we know any of these things, because they can make up scenarios within which we would believe such things even though they would be false, and we cannot know for sure that we are not actually such a scenario. But these days, few epistemologists are inclined to accept radical skepticism, and thus allow that we can know things even if the way in which we achieved that knowledge is fallible. High standards still need to be met, in order for something to qualify as knowledge rather than some weaker form of true belief; but these standards do not require us to be invulnerable to error. It is enough that they are met and no error has actually been committed. ${ }^{2}$

*James F. Miller Professor of Humanities, Lewis \& Clark College, USA.

1. I am indebted to Ian Evans for an earlier collaboration in which we worked on this topic together, and from which most of what appears in this paper derives.

2. I put this in a way that is deliberately ambiguous: The "no error" rule is typically used not only to require that knowledge has a truth condition, but also to 
If we accept this fallibilist approach, then, we might accept that we really do know the examples above. But each of these has an interesting-and recently very controversial feature: Each of these beliefs, at least for most of us, is based on the testimony of others. The first two beliefs in the list we might call historical beliefs; they are beliefs about events before some of us were born. Clearly, any justification you have for historical beliefs must rely heavily on the testimony of others (whether that be from historical documents, textbooks, or conversation with a friend). The second two beliefs in the list we can call scientific beliefs; they are beliefs about scientific matters. A great many - probably most - scientific beliefs regard subject matters in which most of us are not experts. In such cases, most of us rely almost entirely on the expertise of scientists. ${ }^{3}$

Historical and scientific beliefs are but two categories of belief that depend heavily or entirely on testimony. And there are many others. To name but one other example: think of someplace you have never been, but may regard yourself as knowing some things about that place (such as, for example, the name of some city there). Since the only way you receive evidence about places you have never been is from what has been reported by others, the knowledge you have in such cases derives from testimony. ${ }^{4}$

So a moment's reflection reveals that our body of beliefs depends heavily - perhaps ineliminably - on the testimony of others. This raises an immediate worry: Is the testimony of others really very reliable? At first glance, it does not seem like it. People lie. People say things about which they have no knowledge. News reporters are often lazy in checking their facts. And politicians are notorious for misleading their constituents. Testimony, it would seem, is a rather fragile basis for our beliefs, much less for knowledge.

But perhaps testimony is reliable; perhaps lies, deception, and laziness are the exceptions that prove the rule. Still, if we are to base our beliefs on

avoid Gettier problems. Gettier problems seem to require that some error is made in the process of justification. I do not simply assume this approach provides an adequate answer to the Gettier problem, however; I intend only to report a common response to that problem, which I now set aside as not pertinent to the problem that is the focus of this paper.

3. Even the scientist who does some of the key experiments that establish a scientific belief relies on the testimony of others: inevitably, many (most?) of the data he uses will have come from the reports of other scientists. So even the scientist who does the experiments proving the existence of tectonic plates believes in those plates at least partly on the basis of testimony.

4. By "testimony," I obviously include non-verbal information, as well, such as photographs, maps, etc. In brief, I take any evidence that comes from another human source to count as testimony for my purposes herein. Obviously, there are other types of evidence-such as what we receive from ordinary perception, memory, reasoning, and so on. 
testimony-beliefs that we think are at least candidates for knowledge, then do not we need to know that such testimony is reliable? And would not we have to gain such knowledge without relying on testimony? But without recourse to things we learned from others, would we really have enough resources to justify our trust in testimony?

This problem, which has received a great deal of attention lately from epistemologists, is, I claim, actually a version of a much older and better known problem: the so-called problem of the criterion. I will first explain this other, older, problem, and lay out the available options for solving it. I will then show why I think the problem of testimony is simply a version of the problem of the criterion. I will conclude by arguing that the best way to solve these problems comes from a theory of justification that few epistemologists seem to support these day. In doing so, I hope I will provide some powerful new reasons for reconsidering this theory of justification.

\section{The Problem of the Criterion}

A general principle that generates what is called the problem of the criterion might be the reliable source doctrine:

Reliable Source Doctrine (RSD). A belief source $K$ can produce justified beliefs for $S$ only if $S$ is justified in believing that $K$ is reliable.

We obviously believe that some belief sources are reliable and others are unreliable. Given this fact of epistemic life, it would seem like a bad policy to trust a belief source blindly before we know whether it is reliable. Now to make the problem of the criterion concrete, consider a particular belief source, sense perception. If knowledge requires justification, and RSD is true, then we cannot know that something we come to believe through perception is true unless we are justified in believing that sense perception is reliable. Of course, intuitively, we are justified in thinking that at least some belief acquisition via sense perception is reliable. A problem arises, however, when we reflect on how we might get such justification. It seems that the only way we can learn about the reliability of sense perception is through experience. You might, for example, discover that your ability to recognize faces at 500 yards or more is very unreliable by seeing faces from that distance and then getting closer to confirm or disconfirm who you thought you saw. And, of course, psychologists who study our perceptual faculties run all sorts of interesting experiments that teach us about where and when our faculties are reliable and unreliable. But now there seems to be a real problem, which I will call the "skeptical problem of the criterion for sense perception:" 
1. Sense perception can produce justified beliefs for us only if we are justified in believing that sense perception is reliable.

2. We can be justified in thinking that sense perception is reliable only if we have justified perceptual beliefs that provide support for this conclusion.

3. Either (i) we must have justification for thinking that sense perception is reliable prior to gaining justification for our sensory beliefs, or (ii) we must have justification for our sensory beliefs prior to gaining justification for thinking that sense perception is reliable.

4. By 2, (i) cannot be the case.

5. By 1, (ii) cannot be the case.

6. Hence, sense perception cannot produce justified beliefs.

The argument, in a nutshell, says that since we need to be justified in thinking that sense perception is reliable before it can produce justified beliefs, and that the only way to find out whether sense perception is reliable is to use justified beliefs generated by sense perception, there is no way for sense perception to generate justified beliefs. This skeptical conclusion obviously generalizes to other belief-sources like memory, deduction, and induction.

If we want to avoid skepticism, we will have to reject one of the first three premises of this argument. Which premise we reject will determine which sort of theory of justification we endorse.

Dogmatism is the view that rejects premise 1 (and accepts 2). Dogmatists think that we can get justified beliefs from, for example, some belief-source (again, such as sense perception) even if we are not justified in believing that the belief-source is reliable.

Reductionism is the view that rejects premise 2 (and accepts 1 and 3). Reductionists claim that our justification for thinking that some belief-source is reliable derives from the justification we have in believing that some other (prior) mode of belief acquisition is reliable, and our justification for believing in the reliability of the dependent belief-source derives entirely from the justification provided by that other (prior) mode of belief acquisition.

Holistic Coherentism is the view that rejects premise 3 (and accepts 1 and 2). Holistic coherentists do not think that the justification for either sort of belief is prior to the other - it is only when we have enough together in a coherent way that any of them become justified; and then they become justified all at once.

Some may find my account of the second sort of strategy unfamiliar, but that is only because of the specific example of perception that I have used. The only form of reductionism I have ever heard of, with respect to sense perception, has been called "apriorism," according to which we have a priori justification for thinking that sense perception is reliable and that this is what enables sense perception to produce justified beliefs for us. Apriorism is the view most associated with Descartes, who sought an a priori proof that a non- 
deceiving God exists and endowed us with reliable sensory faculties. The perceived failure of Descartes's project provided much of the impetus for the rise of contemporary dogmatism. But apriorism is "reductionist" in the sense just described, because it holds that our justification for thinking that sense perception is reliable derives entirely from our justification in believing in whatever a priori justification is provided in support. Of course, the apriorist must then face the problem of the criterion again with respect justification $a$ priori. And that same postponement of the problem of the criterion will be found in any other form of reductionism, as well: once the justification for believing some process is reliable is identified in some other process, then the problem of the criterion will appear again with respect to that other process. At any rate, there is a reason why I have subsumed apriorism under the general heading of "reductionism," and that reason will become clear in a bit.

\section{The Problem of Testimony as a Version of the Problem of the Criterion}

Recent discussions of the problem of testimony have not actually identified the problem as a version of the problem of the criterion, but I hope the brief survey of that problem makes clear enough how and why the problem of testimony is simply a variant of this more familiar problem. In brief, the problem of testimony creates the problem of the criterion by substituting belief acquisition via testimony into principle RSD, as follows:

Reliable Source Doctrine for Testimony (RSDt). Testimony can produce justified beliefs for $S$ only if $S$ is justified in believing that testimony is reliable.

We can then simply replace sense perception with testimony in the skeptical argument I gave before to see how testimony has become a problem for epistemologists:

1. Testimony can produce justified beliefs for us only if we are justified in believing that testimony is reliable.

2. We can be justified in thinking that testimony is reliable only if we have justified beliefs that derive from testimony, which provide support for this conclusion.

3. Either (i) we must have justification for thinking that testimony is reliable prior to gaining justification for the beliefs we derive from testimony, or (ii) we must have justification for the beliefs we derive from prior to gaining justification for thinking that beliefs we derive from testimony are reliable.

4. By 2, (i) cannot be the case.

5. By 1 , (ii) cannot be the case.

6. Hence, testimony cannot produce justified beliefs. 
Again, our options for justifying our trust in testimony are three: dogmatism (rejecting premise 1), reductionism (rejecting premise 2), and holistic coherentism (rejecting premise 3). It is worth remarking that many important general theories of justification are versions of dogmatism ${ }^{5}$ and many other import theories of justification are versions of holistic coherentism, ${ }^{6}$ though dogmatism seems to be the more common view.

My aim here is not to survey all these views - excellent critical surveys already exist.7 Instead, I will first take up examine a recent (and influential) dogmatist theory and notice a serious problem - a problem that is shared by all versions of dogmatism, including those epistemologists have attempted to apply to the problem of testimony.

\section{Dogmatism and the Problem of Easy Knowledge}

Distinctive of dogmatism is the claim that some belief sources can produce justified beliefs for $S$ even if $S$ does not know that such sources are reliable. A recent influential version of dogmatism with respect to sense

5. See, for examples, Conee and Feldman's "evidentialism" (2004), BonJour's (2001) and Fumerton's (1995) defense of traditional foundationalism, Norman's unjustified foundationalism (1997), Leite's "localism" 2005, and (for basic logical knowledge) Wright (2001). [Earl Conee and Richard Feldman, Evidentialism: Essays in Epistemology (Oxford: Oxford University Press, 2004); Laurence BonJour, "Toward a Defense of Empirical Foundationalism," in Resurrecting Old-Fashioned Foundationalism, ed. Michael. R. DePaul (Lanham, MD: Rowman and Littlefield, 2001); Richard A. Fumerton, Metaepistemology and Skepticism (Lanham, MD: Rowman and Littlefield, 1995); Andrew Norman, "Regress and the Doctrine of Epistemic Original Sin," The Philosophical Quarterly 47, no. 189 (1997); Adam Leite, "A Localist Solution to the Regress of Epistemic Justification," Australasian Journal of Philosophy 83, no. 3 (2005); Crispin Wright, "On Basic Logical Knowledge," Philosophical Studies 106, no. 1/2 (2001).] Most forms of externalism also qualify as dogmatist theories, in the sense that they treat our cognitive processes as conferring warrant on their products, but do not require warrant from some other source themselves.

6. So see, for examples, Harman's "negative coherentism" (1973), and the positive coherentisms proposed by Lehrer (2000), BonJour (1985), and most recently (and tentatively) by Cohen (2002). [Gilbert Harman, Thought (Princeton, NJ: Princeton University Press, 1973); Keith Lehrer, Theory of Knowledge (Boulder, CO: Westview Press, 2000); Laurence BonJour, The Structure of Empirical Knowledge (Cambridge, MA: Harvard University Press, 1985); Stewart Cohen, "Basic Knowledge and the Problem of Easy Knowledge," Philosophy and Phenomenological Research 65, no. 2 (2002).]

7. Plantinga's 1993 is a notable example, as is Pollock and Cruz 1999. [Alvin Plantinga, Warrant: The Current Debate (Oxford: Oxford University Press, 1993); John L. Pollock and Joseph Cruz, Contemporary Theories of Knowledge, 2nd edn. (Lanham, MD: Rowman and Littlefield, 1999).] 
perception is Pryor's 2000.8 One of the main theses of Pryor's view is the following principle:

PFJ. If (i) Shas an experience as of $p$ 's being the case, (ii) $S$ has no reason to think that her experience is misleading, and (iii) $S$ believes $p$ on the basis of this experience, then $S$ is justified in believing that $p$.

The idea is that, absent a special reason for doubt, you are justified in taking your experiences at face value. If you have an experience as of there being a large red cylinder in front of you, and you believe, on this basis, that there is a large red cylinder in front of you, you will have formed a justified belief (provided that you have no reason for thinking that your experience is misleading in this case).

PFJ explains how we acquire basic, non-inferentially justified beliefs. These basic beliefs will, further, count as evidence for other propositions.

This version of dogmatism has many points in its favor. For one, it avoids the skeptical conclusion of the problem of the criterion. Further, it explains how we can begin to acquire justified beliefs about the world around us even before we know much about our belief-forming processes or their varying degrees of reliability. Finally, it does seem plausible to think that that, if you have an experience as of $p$, then you are justified in taking that experience at face value (absent special reasons for doubt) - at least, it seems as though we ordinarily conduct our epistemic business in this way.

There is, however, a rather serious problem with dogmatism, and it is one that epistemologists have begun to appreciate only recently. Stewart Cohen has called it "the problem of easy knowledge." 9 Let's suppose we are considering a version of dogmatism that entails the following:

E. If (i) $S$ has an experience as of $O$ being the color $X$, (ii) $S$ has no reason to think that her experience is misleading, and (iii) $S$ believes $O$ is the color $X$ on the basis of this experience, then $S$ is justified in believing that $\boldsymbol{O}$ is the color $\boldsymbol{X}$.

It is an intuitive enough principle. If something looks red to you, that is all the reason you need for thinking that it is red. One way of encountering the problem of easy knowledge, however, is via what is known as the closure principle:

8. Pryor's theory of justification appears to be a somewhat less detailed version of John Pollock's 1974 defeasible reasons theory. [James Pryor, "The Skeptic and the Dogmatist," Noûs 34, no. 4 (2000); John L. Pollock, Knowledge and Justification (Princeton, NJ: Princeton University Press, 1974).] I present it instead of Pollock's because (a) it has recently received a lot of attention, and (b) the nuances of Pollock's view do not concern us here.

9. Cohen, "Basic Knowledge and the Problem of Easy Knowledge." 
Justification Closure. If $S$ justifiedly believes that $p$, and $S$ competently deduces $q$ from $p$, then $S$ justifiedly believes that $q$.

This principle is also quite intuitive. If you grant that someone is justified in believing that $p$, and you agree with them that $p$ entails $q$, how on earth could you fault them for thereby believing $q$, once they have made the deduction? Consider now the version of the closure principle for knowledge:

Knowledge Closure. If $S$ knows that $p, p$ entails $q$, and $S$ competently deduces $q$ from $p$, then $S$ knows that $q$.

If justification is required for knowledge, it is hard to see how Knowledge Closure could be true but Justification Closure false. ${ }^{10}$ But dogmatism seems to require precisely this. To see why, consider the following case: Suppose Plum has an experience as of $\boldsymbol{O}$ being red and has no reason for thinking this experience is misleading. He forms the belief that $\boldsymbol{O}$ is red on the basis of experience. According to E, Plum is justified in believing that $\boldsymbol{O}$ is red. But if $\boldsymbol{O}$ is red, this entails that $\boldsymbol{O}$ is not white with red lights shining on it, and Plum knows this. So suppose Plum competently deduces that $O$ is not white with red lights shining on it. Is he thereby justified in believing that $\boldsymbol{O}$ is not white with red lights shining on it? It is not so clear that he is. Imagine the following conversation at a furniture store: ${ }^{11}$

Dad: Here you go son, this is a fine red table for your room.

Son: But Dad, how do you know it is not a white table with red lights shining on it?

Dad: Well, Son, it looks red, so it is red. And if it is red, then it is not white with red lights shining on it.

Son: ?!

The "reason" Dad gives Son for thinking that the table is not white under red lighting is patently absurd. Ordinarily, of course, Dad would be justified in believing that the table is not white with red lights shining on it - only the skeptic denies that - but surely Dad cannot know this simply by carrying out the absurd reasoning above. Justification that the table is not white with red lights shining on it is simply not that easy to come by - it depends on all sorts of other knowledge (such as how often furniture stores have red lights, how a white table under red lights usually differs in appearance from a red table under white lights, and so on).

Now, it might be objected at this point that Son has actually given Dad a reason not to believe that the table is red, and so requirement (ii) of principle

10. Some epistemologists have denied versions of closure. This is plainly not the place to review this issue, however.

11. Cohen, "Basic Knowledge and the Problem of Easy Knowledge," 315. 
E is no longer met in this case. The problem is that PFJ seems to supply Dad with sufficient grounds not to suppose that the reason Son has provided is defeated: as soon as Dad has perceived the table as being red, PFJ ensures that he now has a reason to believe that it is red. But if it is red, it is not white, and Dad knows this. So, the reason Dad has for thinking that the table is red is a defeater for the claim that it is white. Hence, PFJ would allow Dad to reject Son's proposal in precisely the way the case presents. Defeated "reasons" for not making the inference ensured by PFJ do not block the inference.

But even without closure, we encounter the problem of easy knowledge. It is often seen as a virtue of dogmatism that it can explain how we do eventually come to know that perception is reliable. Once we have a complete enough picture of the world around us and our perceptual faculties (which PFJ explains how we can acquire), we can then infer various things about the reliability of our faculties. Dogmatism seems to be in a good position to explain how, for example, modern vision science is possible.

But if dogmatism is right, there is a much easier way of determining whether our color vision is reliable - a way that is much too easy. Suppose Son asks Dad whether color vision is reliable. Dad picks up a stack of colored construction paper and tells Son that they can investigate the matter together:

(Dad picks up a red piece of paper.)

Dad: Well, this one is red. And it looks red. So color vision worked that time.

(Dad picks up a blue piece of paper.)

Dad: Let's see ... this one is blue. And, why, what do you know - it looks blue. Color vision worked again!

(Hundreds of sheets later.)

Dad: Well, son, our color vision got it right 345 times out of 345 . That seems pretty darn reliable to me!

Once again, this procedure is patently absurd. Surely this is no way of coming to justifiedly believe that color vision is reliable! The trouble is, according to principle $\mathbf{E}$, there is nothing wrong the procedure. For each time Dad flips over a piece of paper and sees that the paper is color $X, \mathrm{E}$ says that Dad justifiedly believes that the paper is color $X$. Furthermore, if something looks color $X$ to us, dogmatists will presumably allow that we can justifiedly believe that some looks color $\boldsymbol{X}$ to us. But if we assume that enumerative induction is a way of gaining knowledge of reliability - and how else could we learn about reliability? - then the dogmatist will have to allow that Dad's procedure is a good one. But this is an unacceptable result. For all its intuitive appeal, dogmatism makes knowledge about our reliability much too easy. 


\section{Application to the Problem of Testimony}

Two general sorts of responses have been given to the problem of testimony, and we are now in a better position to see what is wrong with at least one of these approaches:

Reductionism. Our justification for testimonial beliefs comes from perceptual evidence that testimony is reliable (which evidence does not itself depend on testimony). ${ }^{12}$

Anti-Reductionism. Our justification for testimonial beliefs is basic - if someone tells you that $p$, then that gives you justification for believing that $p$, unless you have some special reason to doubt $p$ or the trustworthiness of the testifier. ${ }^{13}$

I hope it is now clear why I earlier identified one of the general strategies for answering the problem of the criterion as "reductionist." As I said, the only form of reductionism that I know to have been applied to the problem of the criterion with respect to sense perception was a reduction of the justification for the belief in sense perception to some a priori justification. But apriorism has been rejected by contemporary epistemologists, and in any case, this is not the version of reductionism that epistemologists have applied to the problem of testimony, so I will not discuss it any further here. In the case of testimony, reductionism has taken a different form: reductionists claim that we are justified in believing in the reliability of testimony, only if we can derive that justification from other (presumably reliable) cognitive processes. As I said earlier, this has the effect of postponing the problem of the criterion with respect to testimony: for now, that problem only arises with respect to

12. A classic statement of reductionism can be found in Hume's Enquiry, Part 1, para. 4-5. Adler 1994, Fricker 1994, and Lyons 1997 are more recent examples. [Jonathan E. Adler, "Testimony, Trust, Knowing," Journal of Philosophy 91, no. 5 (1994); Elizabeth Fricker, "Against Gullibility," in Knowing from Words: Western and Indian Philosophical Analysis of Understanding and Testimony, ed. A. Chakrabarti and B. K. Matilal (Dordrecht: Kluwer Academic Publishers, 1994), 125-161; Jack Lyons, "Testimony, Induction and Folk Psychology," Australasian Journal of Philosophy 75, no. 2 (1997).]

13. A classic statement of anti-reductionism can be found in Reid's Inquiry, chapter 6, sec. 24. Coady 1992 and Burge 1997 are important recent defenders of the view. [C. A. J. Coady, Testimony: A Philosophical Study (Oxford: Clarendon Press, 1992); Tyler Burge, "Interlocution, Perception, and Memory," Philosophical Studies 86, no. 1 (1997).] See also Foley 1994 and Audi 2002. [R. Foley, "Egoism in Epistemology," in Socializing Epistemology: The Social Dimensions of Knowledge, ed. Frederick Schmitt (Lanham, MD: Rowman and Littlefield, 1994), 53-74; Robert Audi, "The Sources of Knowledge," in The Oxford Handbook of Epistemology, ed. Paul K. Moser (Oxford: Oxford University Press, 2002), 71-94.] 
the other processes on the basis of which we justify our acceptance of testimony.

The anti-reductionists, with respect to testimony, are plainly providing a version of a dogmatism in their defense of testimony. But like Pryor's version of dogmatism, anti-reductionism with respect to testimony seems to run afoul of the "easy knowledge" problem: Anti-reductionists claim that testimony is a unique source of justification: the fact that someone told you that $p$ is, all by itself, a reason to believe $p$. But if anti-reductionism were right, it would be too easy to find out that a testifier was reliable: you could simply believe everything she says, infer that everything she has ever told you is true, and so conclude that she is very reliable. That, however, would be a very unreasonable way to proceed!

So perhaps the reductionist strategy is more promising. The idea behind reductionism is simple enough. When you receive a bit of testimony, you are often in a position to check it yourself. For example, if a weather forecaster predicts rain in the afternoon then you can simply watch for rain in the afternoon to find out if the forecaster was right. If you do this often enough, you can get a feel for how reliable the forecaster is. If you discover that the forecaster is sufficiently reliable, then in the future you justifiedly believe her predictions. The key point to notice is that your justification would not rely on any sort of ineliminable trust in testimony. Through ordinary perceptual experience you have learned that this forecaster usually gets it right: you have personally verified her reliability.

The reductionist claims that reliance on non-testimonial evidence is the only way testimony can give us justified beliefs. If you believe $p$ on the basis of testimony, then you had better have reason - derived from personal experience - for thinking that the person who told you that $p$ is reliable (in the present circumstances, anyway). Now reductionists do not want to be skeptics. And they recognize that the vast majority of our beliefs are based on testimony. So consider the horde of testifiers on whom you have relied in the past - reporters, authors, scientists, governmental agencies, doctors, strangers, mechanics, advertisers, family, preachers, talk show hosts, Wikipedia, Dictionary.com, etc. The reductionist is committed to claiming that you have done enough personal verification to believe reasonably that most of these testifiers are reliable.

But this is unrealistic. The problem is that there is just far too much information that all of us come to believe-and thus to apply in our judgments of whether or not to accept new information presented to usthrough testimonial sources. We simply do not have the epistemic resources to verify most of what we have come to believe through testimony. Reductionism, then would seem to lead to deep skepticism about most of our beliefs. I see no way to avoid this result, taking a reductionist approach. The only reasonable way to resolve the problem of testimony, I contend, is to 
return to a theory of justification that has very much gone out of style in recent years: holistic coherentism. Recall the reliable source doctrine with respect to:

Reliable Source Doctrine for Testimony ( $\left(\mathbf{R S}_{\mathfrak{t}}\right)$. Testimony can produce justified beliefs for $S$ only if $S$ is justified in believing that testimony is reliable.

The reductionist also embraces RSD $_{\text {. }}$ Butas I have now shown, reductionism leads to skepticism, for without relying on testimonial beliefs, we will not be able to establish the reliability of testimony. But if we look again at the skeptical argument of the problem of thecriterion applied to testimony, we can now fruitfully consider the idea that both reductionists and anti-reductionists are endorsing a false dilemma in premise 3 of that argument:

3. Either (i) we must have justification for thinking that testimony is reliable prior to gaining justification for the beliefs we derive from testimony, or (ii) we must have justification for the beliefs we derive from testimony prior to gaining justification for thinking that beliefs we derive from testimony are reliable.

There is, in fact, a third option: according to the holistic coherentist account, ${ }^{14}$ neither our justification for our testimonial beliefs nor our justification for thinking that testimony is reliable needs to be prior to the other. According to holistic coherentism, beliefs are justified only insofar as they cohere well with a broad system of beliefs that is itself coherent. A sufficiently coherent system of beliefs will include beliefs about the reliability of belief sources (testimony, perception, reason). But these reliability beliefs are themselves justified by their coherence with the rest of the system, not by some antecedent source of justification.

As children, we implicitly trust the testimony of a great many unverified sources. This is a crucial step in acquiring the beliefs that we do. But it is only once we have developed a broad and sophisticated body of beliefs (one which includes beliefs about when and what sort of testimony to trust), that we begin to have justified beliefs. And these beliefs are justified "all at once" beliefs about testimony and beliefs based on testimony becoming justified by fitting together into a broad and coherent system of beliefs. I conclude that holistic coherentism offers the best available account of testimonial justification.

14. Versions of this view may be found in Harman 1973, BonJour 1985, Lehrer 2000, and Cohen 2002. [Harman, Thought; BonJour, The Structure of Empirical Knowledge; Lehrer, Theory of Knowledge; Cohen, "Basic Knowledge and the Problem of Easy Knowledge."] 


\section{Holistic Coherentism and Justification}

Let's reconsider the picture the dogmatist gave us of justification. Her view is that justification for individual beliefs is generated (ex nihilo, as it were) from some source, whether perception, or testimony, or whatever. This justification can then be transferred to other beliefs by means of inference. The problem with this picture is that it creates the problem of easy knowledge.

But consider a different picture of justification. The holistic coherentist suggests that justification for a belief is generated by the overall coherence of the system of beliefs within which it is situated and the degree to which the belief fits into (or coheres with) that system. After enough time in the world, we will form an overall picture of ourselves and our environment (a system of beliefs). If this system has a high degree of coherence, then particular beliefs within the system earn their justification by adding to the overall coherence of the system.

A famous old analogy will help. A large ship at sea keeps the crew out of the water, not in virtue of any particular plank of wood, but because there are numerous planks of wood fitting together in the right way. Any particular plank of wood contributes to the ship's seaworthiness by fitting in its spot and plugging a potential leak. This might be contrasted with a building: What supports a man on the fifth floor is, ultimately, the foundational pillars on the ground - those provide support independently of the rest of the structure, which merely adds height. In the ship, however, each plank is of roughly equal importance and without enough planks, the ship cannot float in the first place.

The holistic coherentist views justification as analogous to a ship at sea. None of our beliefs can be justified until we have enough of them fitting together to have a coherent picture of the world. At that point, and only then, do the beliefs within the system (including beliefs about that system itself) acquire justification "at once" (all those that cohere well, that is). The key thesis for the holistic coherentist is the following:

HC. S's belief that $p$ is justified just in case $p$ coheres well with $S$ 's belief system, which itself has a high degree of coherence.

Critics of holistic coherentism have sometimes confused it with a much less plausible account, which might be called "linear coherentism," according to which justification might go in circles. For the holistic coherentist, no circular inferences take place. If asked what ultimately justifies a belief, the holistic coherentist does not point to another belief, and then another and another until she winds up in a circle. Instead, she points to the fact that the belief fits into a coherent system. 
But now we are in a position to see how we can, in fact, learn that perception and testimony are reliable. As we begin our epistemic lives, we have implicit trust in our perceptual faculties and in testimony we receive. This allows us to acquire a large stock of beliefs from these sources - to exercise our innate cognitive equipment. As time goes on, some of the perceptual beliefs we acquire are about circumstances in which perception seems to work quite well and circumstances in which it does not, and the same goes for testimony. By this point, we have achieved a fairly sophisticated understanding of our own environment and our cognitive faculties. Once we reach this point (and of course, only if our belief system is coherent), by principle $\mathrm{HC}$ both the individual beliefs that derive from sense perception and testimony-and also the beliefs about the reliability of these forms of belief acquisition-acquire justification.

Holistic coherentism, then, provides a solution to the problem of the criterion without encountering the problem of easy knowledge. Holistic coherentists embrace the idea that we must be justified in thinking that perception and testimony are reliable if we are to be justified in our perceptual beliefs. They also endorse the claim that knowledge about the reliability of perception and testimony are based on our experiences of using these sources of belief. What they reject, however, is the idea that there are chronological priority relations between justified beliefs. It is not as though you need to be justified in believing that perception is reliable before you can be justified in using perception (or vice versa). Rather, justification arises once you have both ordinary perceptual beliefs and beliefs about the reliability of perception - the coherence of such a system creates justification all at once. Again, the same goes, mutatis mutandis for our justification in believing in testimony-we are not justified in believing that testimony is reliable before we have formed beliefs based on testimony, nor does the justification process go the other way around. What is more, this solution avoids the problem of easy knowledge, because knowledge (at least, the sort[s]of knowledge that require[s] justification ${ }^{15}$ ) can only be the result of a system that has been built up over time and as a result of both experience and reflection on that experience. I tentatively conclude, then, that some version of holistic coherentism is the best account of epistemic justification, both for perception and for testimony. In fact, I am inclined to think that holistic coherentism is the best general account of all justification, but an argument for that claim would need to survey all of the sources of belief acquisition.

15. I am not at all committed to the claim that knowledge always has justification as a necessary condition. I am committed to the claim that there are at least some cases in which justification is a necessary condition for knowledge. For defense of this view, see the arguments in Evans and Smith [Ian Evans and Nicholas D. Smith, Knowledge (Cambridge: Polity Press, 2012)]. 


\section{Bibliography}

Adler, Jonathan E. "Testimony, Trust, Knowing." Journal of Philosophy 91, no. 5 (1994), 264-275.

Audi, Robert. "The Sources of Knowledge." In The Oxford Handbook of Epistemology, edited by Paul K. Moser, 71-94. Oxford: Oxford University Press, 2002.

BonJour, Laurence. "Toward a Defense of Empirical Foundationalism." In Resurrecting Old-Fashioned Foundationalism, edited by Michael. R. DePaul, 21-48. Lanham, MD: Rowman and Littlefield, 2001.

_.. The Structure of Empirical Knowledge. Cambridge, MA: Harvard University Press, 1985.

Burge, Tyler. "Interlocution, Perception, and Memory." Philosophical Studies 86, no. 1 (1997), 21-47.

Coady, C. A. J. Testimony: A Philosophical Study. Oxford: Clarendon Press, 1992.

Cohen, Stewart. "Basic Knowledge and the Problem of Easy Knowledge." Philosophy and Phenomenological Research 65, no. 2 (2002), 309-329.

Conee, Earl, and Richard Feldman. Evidentialism: Essays in Epistemology. Oxford: Oxford University Press, 2004.

Evans, Ian, and Nicholas D. Smith. Knowledge. Cambridge: Polity Press, 2012.

Foley, R. "Egoism in Epistemology." In Socializing Epistemology: The Social Dimensions of Knowledge, edited by Frederick Schmitt, 53-74. Lanham, MD: Rowman and Littlefield, 1994.

Fricker, Elizabeth. "Against Gullibility." In Knowing from Words: Western and Indian Philosophical Analysis of Understanding and Testimony, edited by A. Chakrabarti and B. K. Matilal, 125-161. Dordrecht: Kluwer Academic Publishers, 1994.

Fumerton, Richard A. Metaepistemology and Skepticism. Lanham, MD: Rowman and Littlefield, 1995.

Harman, Gilbert. Thought. Princeton, NJ: Princeton University Press, 1973.

Lehrer, Keith. Theory of Knowledge. Boulder, CO: Westview Press, 2000.

Leite, Adam. "A Localist Solution to the Regress of Epistemic Justification." Australasian Journal of Philosophy 83, no. 3 (2005), 395-421.

Lyons, Jack. "Testimony, Induction and Folk Psychology." Australasian Journal of Philosophy 75, no. 2 (1997), 163-178.

Norman, Andrew. "Regress and the Doctrine of Epistemic Original Sin." The Philosophical Quarterly 47, no. 189 (1997), 477-494.

Plantinga, Alvin. Warrant: The Current Debate. Oxford: Oxford University Press, 1993.

Pollock, John L., and Joseph Cruz. Contemporary Theories of Knowledge, 2nd edn. Lanham, MD: Rowman and Littlefield, 1999. Knowledge and Justification. Princeton, NJ: Princeton University Press, 1974. 
Pryor, James. "The Skeptic and the Dogmatist." Nô̂s 34, no. 4 (2000), 517-549.

Wright, Crispin. "On Basic Logical Knowledge." Philosophical Studies 106, no. 1/2 (2001), 41-85. 